\title{
Atributos químicos do solo, reservas orgânicas e sistema radicular de pastos degradados associada à introdução de leguminosa ${ }^{1}$
}

\author{
Soil chemical properties, organic reserves and root system of a \\ degraded pasture associated introduction of legume ${ }^{1}$
}

\author{
Carlos Eduardo Santos Fabrice ${ }^{2 *}$; Cecílio Viega Soares Filho ${ }^{3}$; Marcos Franke \\ Pinto $^{3}$; Silvia Helena Venturoli Perri ${ }^{3}$; Ulysses Cecato ${ }^{4}$; Gustavo Pavan Mateus ${ }^{5}$
}

\section{Resumo}

\begin{abstract}
O objetivo do trabalho foi estudar a recuperação de pastos degradados com a introdução do Stylosanthes macrocephala e capitata cv. Campo Grande em pastagem de Brachiaria decumbens cv. Basilisk avaliando os teores de $\mathrm{N}$-total nas raízes, biomassa, área, comprimento e; diâmetro radicular, teores de macro e micronutrientes no solo. O experimento foi realizado na Agência Paulista de Tecnologia dos Agronegócios, no município de Andradina-SP, de fevereiro de 2011 a maio de 2012. O delineamento experimental foi de blocos ao acaso, em esquema de parcelas subdivididas (com e sem adubação fosfatada), com quatro repetições, formando os seguintes tratamentos: controle Brachiaria decumbens (CB); dessecação parcial com 1,5 $\mathrm{L} \mathrm{ha}^{-1}$ de glifosato (DP); dessecação total com 3,0 $\mathrm{L} \mathrm{ha}^{-1}$ de glifosato (DT); plantio direto (PD); escarificação do solo (E); gradagem rome (G) e aração + gradagem (AG). Nos tratamentos $\mathrm{G}$ e $\mathrm{AG}$ a semeadura foi feita a lanço e os demais na forma de semeadura direta. As estratégias de recuperação do pasto de capim-braquiária apresentaram diferenças significativas entre os tratamentos apenas para o teor de $\mathrm{N}$-total, não houveram diferenças para características geométricas das raízes e da biomassa radicular. Os teores de macro e micronutrientes presentes no solo não apresentaram diferenças significativas entre as estratégias de recuperação $(\mathrm{P}>0,05)$. A adubação apresentou efeito significativo para os teores de fósforo. A introdução do estilosantes Campo Grande acompanhados de técnicas como dessecação e aração + gradagem contribuíram para aumentos nos teores de N-total no sistema radicular. As formas de introdução da leguminosa não modificaram os atributos químicos do solo.

Palavras-chave: Biomassa, forragem, nitrogênio, raiz, recuperação, Brachiaria decumbens
\end{abstract}

\begin{abstract}
The aim was to study the recovery of degraded pasture with the introduction of Stylosanthes macrocephala e capitata cv. Campo Grande on Brachiaria decumbens cv. Basilisk evaluating the levels $\mathrm{N}$-total in roots, biomass, area, and length, diameter and root levels of macro and micronutrients in the soil. The experiment was conducted in the municipality of Andradina, São Paulo State, Brazil. The experimental design was a randomized block design in a split-plot (with and without phosphorus), with four replicates, forming the following treatments: control Brachiaria decumbens (CB), partial
\end{abstract}

\footnotetext{
${ }^{1}$ Projeto de Mestrado em Ciência Animal, Faculdade de Medicina Veterinária, UNESP, Campus de Araçatuba, SP. Bolsa financiada pela FAPESP. Processo no 2010/13746-2.

2 Discente do Curso de Mestrado em Ciência Animal, UNESP, Campus de Araçatuba, SP. E-mail: fabrice.c.e.s@hotmail.com

${ }^{3}$ Profs. Drs. do Dept ${ }^{\circ}$ de Apoio, Produção e Saúde Animal, UNESP, Campus de Araçatuba, SP. E-mail: cecilio@fmva.unesp.br; mfpinto@fmva.unesp.br; shvperri@fmva.unesp.br

${ }^{4}$ Prof. Dr. Titular do Dept ${ }^{\text {de }}$ Zootecnia, Universidade Estadual de Maringá, UEL, Maringá, PR. E-mail: ulyssescecato@gmail. com

${ }^{5}$ Pesquisador da Agência Paulista de Tecnologia dos Agronegócios, APTA, Andradina, SP. E-mail: gpmateus@apta.sp.gov.br

* Autor para correspondência
} 
desiccation with $1.5 \mathrm{~L} \mathrm{ha}^{-1}$ of glyphosate (DP), total desiccation with $3.0 \mathrm{~L} \mathrm{ha}^{-1}$ of glyphosate (TD); tillage (T), soil scarification (S); harrowing rome $(\mathrm{H})$ and plowing + disking (PD). Treatments $\mathrm{H}$ and PD were sown by broadcasting and the other in the form of direct seeding. Recovery strategies of grazing signal grass showed significant differences between treatments only for the content of N-total, there were no differences in geometric characteristics of roots and root biomass. The contents of macro and micronutrients in the soil showed no significant differences between the strategies of recovery. Fertilization had a significant effect for P. The introduction of estilosantes Campo Grande accompanied by techniques such as drying and plowing + disking contributed to increases in the $\mathrm{N}$-total levels in the root system. Forms of introduction of legumes did not change the soil chemical properties.

Key words: Biomass, forage, nitrogen, root, recovery, soil

\section{Introdução}

No ecossistema dos pastos, o solo pode ser considerado como um elemento determinante para o crescimento das plantas, pois os seus atributos físicos e químicos atuam diretamente no processo de estabelecimento e desenvolvimento destas plantas (CORDEIRO, 2006). Há evidências de que a degradação física do solo em áreas de pasto, sob sistemas intensivos de exploração, pode causar danos na estrutura do solo pela compactação provocada pelas patas dos animais, a qual prejudica o movimento de ar, água, nutrientes e processos químicos e biológicos reduzindo a produtividade (SOARES FILHO, 2009).

Diversos estudos têm mostrado que a sustentabilidade de pastos cultivados tropicais está relacionada com, o manejo do solo baseado em práticas que maximizem a ciclagem de nutrientes, minimize suas perdas, e priorizem a entrada desses nutrientes com adubações periódicas e aumento da matéria orgânica do solo (DIAS FILHO, 2007). Diante dessa realidade é grande a demanda por tecnologias que possibilitem o restabelecimento da capacidade produtiva dos pastos de forma econômica e sustentável. As leguminosas são capazes de realizar a fixação biológica de $\mathrm{N}$, por meio da simbiose com as bactérias do gênero Rhizobium, representam uma importante fonte desse nutriente para o sistema e de forragem de alta qualidade para produção animal (LOPES et al., 2011). Entre os diversos nutrientes exigidos para a adequada nutrição do estilosantes, o fósforo merece destaque especial, uma vez que junto com o nitrogênio são os nutrientes que promovem os maiores incrementos na produtividade das culturas exploradas economicamente em solos tropicais (PAULINO; DETMANN; VALADARES FILHO, 2006). O estudo do sistema radicular tem sido tema atual de pesquisas, pois é um parâmetro eficaz para avaliação dos efeitos do uso do solo, principalmente no que diz respeito à sua relação com o sistema solo-planta (PAGOTTO, 2001).

O objetivo do trabalho foi promover a recuperação de pastos degradados de Brachiaria decumbens cv. Basilisk em diferentes formas de introdução de estilosantes Campo Grande avaliando os teores de $\mathrm{N}$-total nas raízes, biomassa, área, comprimento, diâmetro radicular e teores de macro e micronutrientes no solo.

\section{Material e Métodos}

O experimento foi conduzidonaárea experimental do Pólo Regional de Desenvolvimento Tecnológico dos Agronegócios do Extremo Oeste no período de fevereiro de 2011 a maio de 2012, no município de Andradina-SP. O clima da região segundo a classificação Köppen é tropical quente e úmido com inverno seco e o solo da área experimental foi classificado como Latossolo Vermelho segundo Santos, Jacomine e Anjos (2006). O solo foi coletado para análise e apresentou as seguintes características químicas: $\mathrm{P}=4 \mathrm{mg} \mathrm{dm}^{-3} ; \mathrm{MO}=13 \mathrm{~g}$ $\mathrm{dm}^{-3} ; \mathrm{pH}=5,1 ; \mathrm{K}=2,2 \mathrm{mmol}_{\mathrm{c}} \mathrm{dm}^{-3} ; \mathrm{Ca}=7,0 \mathrm{mmol}_{\mathrm{c}}$ $\mathrm{dm}^{-3} ; \mathrm{Mg}=5,0 \mathrm{mmol}_{\mathrm{c}} \mathrm{dm}^{-3} ; \mathrm{H}+\mathrm{Al}=15,0 \mathrm{mmol}_{\mathrm{c}} \mathrm{dm}^{-}$ 3; soma de bases $=15,2 \mathrm{mmol}_{\mathrm{c}} \mathrm{dm}^{-3}$; capacidade de troca catiônica $=300 \mathrm{mmol}_{\mathrm{c}} \mathrm{dm}^{-3} ; \mathrm{V}(\%)=50 ; \mathrm{B}=$ 
$0,1 \mathrm{mg} \mathrm{dm}^{-3} ; \mathrm{Cu}=0,6 \mathrm{mg} \mathrm{dm}^{-3} ; \mathrm{Fe}=27,0 \mathrm{mg} \mathrm{dm}^{-3}$; $\mathrm{Mn}=25,0 \mathrm{mg} \mathrm{dm}^{-3} \mathrm{e} \mathrm{Zn}=12,2 \mathrm{mg} \mathrm{dm}^{-3}$.

Os dados climáticos referentes à precipitação (mm), temperaturas médias mínimas e médias máximas correspondentes ao período experimental podem ser visualizados na Figura 1. Nos dias 28 de Junho e 4 de Agosto de 2011 houveram a incidência de geadas na região, que afetaram os pastos, mas não houve comprometimento da leguminosa.

Figura 1. Dados climáticos de precipitação, temperaturas médias mínimas e médias máximas observadas durante todo o período experimental.

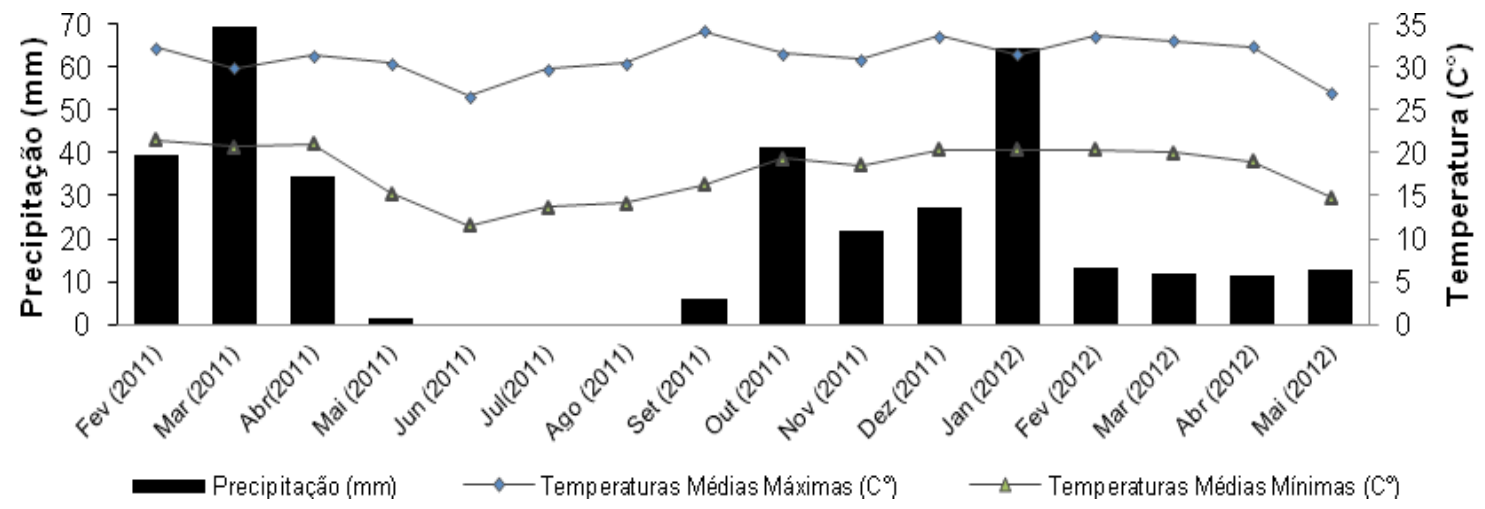

Fonte: Dados do Centro integrado de informações agrometeorológicas e Elaborado pelos autores.

O experimento foi instalado no dia $(02 / 02 / 2011)$ em uma área de $3.500 \mathrm{~m}^{2}$ de pasto degradado de Brachiaria decumbens cv. Basilisk estabelecida há cerca de dez anos, com baixa produção, mas sem grandes infestações de plantas invasoras, onde foi introduzida a leguminosa estilosantes cv. Campo Grande (S. capitata 80\% e S. macrocephala 20\%). O delineamento experimental em blocos casualizados com parcelas subdivididas com quatro repetições. O tamanho das parcelas foi de $10 \mathrm{~m} \times 10 \mathrm{~m}=100$ $\mathrm{m}^{2}$ cada. Os tratamentos foram: controle Brachiaria decumbens (CB); dessecação parcial com 1,5 L/ha de glifosato (DP); dessecação total com 3,0 L/ha de glifosato (DT); plantio direto (PD); escarificação do solo (E); gradagem rome $(\mathrm{G})$ e aração + gradagem (AG). Nos tratamentos G e AG a semeadura foi feita a lanço e os demais na forma de semeadura direta. Nas subparcelas foram avaliadas a presença ou ausência de adubação fosfatada, sendo adubado com $60 \mathrm{~kg}$ de $\mathrm{P}_{2} \mathrm{O}_{5}$ por hectare na forma de superfosfato simples $\left(20 \%\right.$ de $\left.\mathrm{P}_{2} \mathrm{O}_{5}\right)$. A leguminosa foi introduzida no dia $(07 / 02 / 2011)$ na quantidade de $5 \mathrm{~kg} \mathrm{ha}^{-1}$ de sementes com valor cultural de $92 \%$ e espaçamento de 0,225 m entre linhas.
A avaliação do sistema radicular foi realizada ao final do experimento, no pasto consorciado estratificado nas profundidades de 0 a $10 \mathrm{~cm}$ e 10 a $20 \mathrm{~cm}$, coletando três sub-amostras por parcela com, um tubo cilíndrico com $10 \mathrm{~cm}$ de diâmetro e volume de $0,3848 \mathrm{~m}^{3}$. As amostras foram acondicionadas em saco plástico resistente, identificadas e imediatamente encaminhadas a uma câmara fria, com temperatura de $-5^{\circ} \mathrm{C}$. As raízes foram separadas do solo através de lavagens sucessivas em água corrente em peneiras com malha de 1,0 $\mathrm{mm}$ até que não fosse mais possível identificar qualquer contaminação com solo. Em seguida as amostras de raízes foram imersas em solução de água e álcool a $30 \%$ por 12 horas para posterior secagem em estufa com circulação forçada de ar a $65^{\circ} \mathrm{C}$ até peso constante. De cada amostra foi retirada uma alíquota de $1 \mathrm{~g}$ para determinar a densidade $\left(\mathrm{mm} \mathrm{dcm}^{-3}\right)$, a área $\left(\mathrm{mm}^{2}\right)$, o diâmetro $(\mathrm{mm})$ e o comprimento $(\mathrm{mm})$ das raízes por meio do aparelho DELTA T SCAN equipado com o software de análise de imagem de raízes. 
A biomassa radicular foi determinada em função da massa de raízes e volume do cilindro. Posteriormente, as raízes foram moídas em moinho do tipo faca Willey, para a determinação da concentração de nitrogênio total pelo método do micro Kjeldhal (AOAC., 1990). Foram coletadas amostras do solo ao final do experimento para realização de análise química a fim de se determinar os teores de matéria orgânica (M.O), pH, $\mathrm{P}, \mathrm{K}, \mathrm{Ca}$, $\mathrm{Mg}, \mathrm{Al}, \mathrm{H}, \mathrm{H}+\mathrm{Al}, \mathrm{S}, \mathrm{B}, \mathrm{Cu}, \mathrm{Fe}, \mathrm{Mn}, \mathrm{Zn}$, soma de bases (SB), capacidade de troca catiônica (CTC) e saturação por base (V\%).

Os dados foram testados quanto à normalidade dos erros e homogeneidade de variâncias e as análises estatísticas foram realizadas utilizando-se o programa Statistical Analysis System, versão 9.1 (SAS, 1999), no procedimento GLM para o modelo de parcelas subdivididas, sendo os estabelecimentos considerados como parcela principal e o adubo como sub-parcela. Os resultados foram submetidos à análise de variância (ANOVA), teste $\mathrm{F}$ e teste Tukey para a comparação múltipla de médias, a 5\% de significância.

\section{Resultados e Discussão}

Com os resultados obtidos verificou-se que a recuperação de pastagens de capim-braquiária apresentaram diferenças significativas, apenas para N-total das raízes nas profundidades de 0-10 e 10-20 cm (Tabela 1). Não houveram interação entre tratamentos e adubação fosfatada. Para efeito da adubação não foram observadas diferenças significativas. $\mathrm{O}$ teor de $\mathrm{N}$-total na camada de 0 a $10 \mathrm{~cm}$ foi superior para $\mathrm{DP}$ em relação à $\mathrm{CB}$ e $\mathrm{PD}$, porém não diferindo dos outros tratamentos (Tabela 1). Resultados de aumento foram observados por
Beloni et al. (2012), trabalhando com adubação nitrogenada no capim-Mombaça (Panicum maximum cv. Mombaça) e Rodrigues et al. (2007) que obtiveram aumentos na base do colmo e de raiz em capim-Xaraés (Brachiaria brizantha cv. Xaraés), demonstrando dessa forma que o maior acumulo está relacionado com a região mais superficial, resultado das melhores condições nutricionais e disponibilidade hídricas nesta porção de solo. De acordo com Cecato et al. (2004) o aumento nos teores de N-total nos órgãos de reservas promovido pelos maiores teores de $\mathrm{N}$ podem ser um fator favorável após a desfolha, tanto por corte ou pastejo, sendo um elemento importante para o desenvolvimento e crescimento das plantas forrageiras, pois acelera a formação e alongamento de novas folhas, melhora o vigor de rebrota, acelerando sua recuperação após pastejo, resultando em maior produção e capacidade suporte das pastagens ao longo das estações do ano.

Na profundidade de $10-20 \mathrm{~cm}$ houve diminuição de $6,7 \%$ nas médias dos teores de N-total, sendo que as maiores concentrações foram encontradas nos estabelecimentos com dessecação, gradagem e aração + gradagem. Soares Filho (2009) obteve resultados semelhantes ao observar maiores concentrações de N-total na camada de 0 a $10 \mathrm{~cm}$ em pastos de capim-Tanzânia fertilizados com doses de N. De acordo com Lemaire e Chapman (1996), cerca de $80 \%$ do $\mathrm{N}$ presente na parte aérea, formada na primeira semana após o corte ou pastejo, provem da translocação a partir de raízes e hastes, sendo o restante oriundo da absorção via solo. Entretanto, o padrão de remobilização dessas reservas nitrogenadas até novo tecido está associado à quantidade de $\mathrm{N}$ presente no sistema solo-planta (CORSI; MARTHA; PAGOTTO, 2001). 
Tabela 1. Médias das concentrações de N-total, características geométricas (área, diâmetro, comprimento) e biomassa radicular das raízes de estilosantes Campo Grande e Brachiaria decumbens coletados a $(0-10$ e 10-20 cm) de profundidades do solo em diferentes formas de introdução da leguminosa com e sem adubação fosfatada.

\begin{tabular}{|c|c|c|c|c|c|c|c|c|c|c|}
\hline \multirow[t]{2}{*}{ Tratamentos } & $\begin{array}{l}\text { N-total } \\
\left(\mathrm{g} \mathrm{kg}^{-1}\right)\end{array}$ & $\begin{array}{c}\text { Área } \\
\left(\mathrm{mm}^{2}\right)\end{array}$ & $\begin{array}{c}\text { Diâmetro } \\
(\mathrm{mm})\end{array}$ & $\begin{array}{c}\text { Comprimento } \\
\text { (mm) }\end{array}$ & $\begin{array}{c}\text { Biomassa } \\
\left(\mathrm{kg} \mathrm{m}^{-3}\right)\end{array}$ & $\begin{array}{l}\text { N-total } \\
\left(\mathrm{g} \mathrm{kg}^{-1}\right)\end{array}$ & $\begin{array}{l}\text { Área } \\
\left(\mathrm{mm}^{2}\right)\end{array}$ & $\begin{array}{c}\text { Diâmetro } \\
(\mathrm{mm})\end{array}$ & $\begin{array}{l}\text { Comprimento } \\
(\mathrm{mm})\end{array}$ & \multirow[t]{2}{*}{$\begin{array}{c}\text { Biomassa } \\
\left(\mathrm{kg} \mathrm{m}^{-3}\right)\end{array}$} \\
\hline & & & $--(0-10$ & cm)-------- & & \multicolumn{4}{|c|}{ - } & \\
\hline $\mathrm{CB}$ & $0,80 \mathrm{~b}$ & 2483,26 & 0,55 & 4504,18 & 4,96 & $0,68 \mathrm{~b}$ & 2793,07 & 0,58 & 4755,90 & 1,08 \\
\hline DT & $1,09 \mathrm{ab}$ & 3038,95 & 0,49 & 6145,32 & 3,35 & $1,06 \mathrm{a}$ & 2938,22 & 0,56 & 5250,68 & 1,63 \\
\hline DP & $1,30 \mathrm{a}$ & 3379,13 & 0,56 & 6078,22 & 3,88 & $1,11 \mathrm{a}$ & 2624,83 & 0,53 & 4924,93 & 1,15 \\
\hline PD & $0,86 \mathrm{~b}$ & 2887,42 & 0,56 & 5281,02 & 6,77 & $0,71 \mathrm{~b}$ & 2202,17 & 0,70 & 3230,28 & 1,21 \\
\hline E & $0,97 \mathrm{ab}$ & 1878,50 & 0,37 & 5194,57 & 5,64 & $0,75 \mathrm{~b}$ & 2378,56 & 0,46 & 5272,60 & 2,10 \\
\hline G & $1,09 \mathrm{ab}$ & 2742,78 & 0,57 & 5587,72 & 4,73 & $0,93 \mathrm{ab}$ & 3297,25 & 0,57 & 5763,85 & 1,76 \\
\hline $\mathrm{AG}$ & $1,13 \mathrm{ab}$ & 2695,82 & 0,48 & 5523,85 & 7,26 & $1,06 \mathrm{a}$ & 3354,24 & 0,53 & 6464,23 & 1,44 \\
\hline Sem adubo & 1,06 & 2793,26 & 0,52 & 5652,33 & 5,49 & 0,93 & 2762,06 & 0,54 & 5192,91 & 1,27 \\
\hline Com adubo & 1,01 & 2661,08 & 0,51 & 5294,77 & 4,96 & 0,88 & 2834,60 & 0,58 & 4996,37 & 1,69 \\
\hline CV(\%) & 7,53 & 38,02 & 36,68 & 30,08 & 18,35 & 12,71 & 15,50 & 32,31 & 25,75 & 25,26 \\
\hline
\end{tabular}

$\mathrm{CB}=$ controle Brachiaria decumbens; $\mathrm{DT}=$ dessecação total; $\mathrm{DP}=$ dessecação parcial; $\mathrm{PD}=\mathrm{Plantio}$ direto; $\mathrm{E}=$ escarificação do solo; $\mathrm{G}=$ gradagem; $\mathrm{AG}=$ aração + gradagem; $\mathrm{CV}(\%)=$ coeficiente de variação. Médias seguidas por letras diferentes na mesma coluna diferem entre si a $5 \%$ de probabilidade pelo teste de Tukey.

Fonte: Elaboração dos autores.

As características geométricas (área, diâmetro e comprimento) e biomassa radicular não apresentaram diferenças significativas entre os estabelecimentos. $\mathrm{O}$ diâmetro variou entre os tratamentos de 0,37 a $0,56 \mathrm{~mm}$ para coleta a 10 $\mathrm{cm}$ de profundidade e 0,53 a $0,70 \mathrm{~mm}$ para $20 \mathrm{~cm}$, sendo estes resultados próximos aos obtidos por Quadros et al. (2004) dos quais variaram de (0,41 a $0,55 \mathrm{~mm}$ ) trabalhando com Stylosanthes guianensis cv. Mineirão. O baixo crescimento do sistema radicular pode ser explicado pela deficiência de $\mathrm{N}$, sendo menor em pastos degradados, estes resultados foram observados por Muller et al. (2001) em pasto degradado de capim-colonião em comparação a um pasto produtiva.

A biomassa radicular não apresentou diferenças significativas entre as estratégias de recuperação, sendo o maior acúmulo na profundidade de 0 a $10 \mathrm{~cm}$ (Tabela 1). Esse resultado é superior ao encontrado por Volpe et al. (2008) que obtiveram $64 \%$ da biomassa radicular na camada de 0 a $10 \mathrm{~cm}$, trabalhando com renovação de pastos degradados com a utilização de calagem, adubação e consorciação de Brachiaria brizantha cv. Marandu com estilosantes Campo Grande e inferiores aos encontrados por Soares Filho (2009) que obteve $81,7 \%$ da biomassa radicular na camada superficial de 0 a $10 \mathrm{~cm}$ trabalhando com o capimTanzânia submetido à adubação nitrogenada. A maior concentração de raiz nessa região pode ser explicada pelas melhores condições nutricionais e não houve um alto déficit hídrico que desse condição ao desenvolvimento do sistema radicular em maiores profundidades. Segundo Cunha et al. (2010), o sistema radicular reduz o raio de ação da planta para obtenção de nutrientes do solo, o que exigira maior concentração de nutrientes em um menor volume de solo.

Os macronutrientes presentes no solo não apresentaram diferenças significativas entre os tratamentos. Não houve interação entre as formas de introdução da leguminosa e a adubação fosfatada. A adubação teve efeito significativo apenas para os teores de P (Tabela 2). De maneira geral, não houve variação da coleta inicial e final do experimento entre os tratamentos. O índice de pH não apresentou diferenças significativas, porém, os valores poderiam ter sofrido uma diminuição 
com teores maiores de nitrogênio no solo, segundo (FOLLETT.; FOLLETT; HALVORSON, 1992) a redução do $\mathrm{pH}$ com o aumento de nitrogênio é explicada pela transformação de amônia em nitrato, pelo processo de nitrificação. Cunha et al. (2010) observaram menores valores de $\mathrm{pH}$ no solo nos quais o estilosante foi utilizado como cultura de cobertura, sendo melhor que no solos com crotalária, sorgo, braquiária e milheto.

O teor de matéria orgânica não diferiu entre os tratamentos variando de 10,75 a 12,87 $\mathrm{g} \mathrm{dm}^{-3}$ (Tabela 2), sendo menor do que o encontrado por Andrade, Stone e Silveira (2009) que obtiveram valor de 18,6 $\mathrm{g} \mathrm{dm}^{-3}$, trabalhando com estilosante. Esse aumento é explicado devido a solos de mata geralmente apresentam maior conteúdo de M.O do que solos cultivados e pastos degradados. Volpe et al. (2008) também não observaram diferenças significativas para M.O ao estudar renovação de pasto degradado com utilização de calagem, adubação e leguminosa consorciada.

Apesar dos teores de $\mathrm{P}$ não apresentarem diferenças significativas entre as formas de introdução da leguminosa, o efeito da adubação fosfatada foi observado dentro de cada estratégia de recuperação. Estudos conduzidos em pasto de Brachiaria decumbens, consorciada com Pueraria phaseoloides sugerem que os pastos consorciados com leguminosas são mais eficientes em estimular a ciclagem de fósforo, quando comparados aos puros de gramínea (GUGGENBERGER et al., 1996; OBERSON et al., 2001). A explicação está relacionada a maiores taxas de decomposição das raízes e da liteira nos pastos consorciadas. Esse aumento nas taxas de decomposição fornece um fluxo estável de fósforo orgânico para o solo e, como consequência, incentiva a ciclagem e disponibilidade desse elemento para as plantas (DIAS FILHO, 2007). A principal função do $\mathrm{P}$ nas plantas está relacionada com o metabolismo energético via síntese de ATP (adenosina trifosfato). Todos os processos metabólicos das plantas relacionados com os gastos de energia possuem participação direta ou indireta do fósforo. Além disso, pode-se destacar que o fósforo também está relacionado com o crescimento das raízes (LUZ; HERLING; SANCHEZ, 2011).

Tabela 2. Médias dos teores de macronutrientes presentes no solo na consorciação de estilosantes Campo Grande e Brachiaria decumbens em diferentes formas de introdução da leguminosa com e sem adubação fosfatada.

\begin{tabular}{crrrrrrrrrr}
\hline Tratamentos & $\begin{array}{r}\mathrm{pH} \\
\mathrm{g} / \mathrm{dm}^{3}\end{array}$ & $\begin{array}{r}\mathrm{M} . \mathrm{O} \\
\mathrm{g} / \mathrm{dm}^{3}\end{array}$ & $\mathrm{P}$ & $\mathrm{H}+\mathrm{Al}$ & $\mathrm{K}$ & $\mathrm{Ca}$ & $\begin{array}{c}\mathrm{Mg} \\
-----------------------m o l / \mathrm{dm}^{3}------------------\end{array}$ & $\begin{array}{r}\mathrm{S} \\
(\%)\end{array}$ \\
\hline $\mathrm{CB}$ & 5,0 & 12,1 & 2,2 & 13,7 & 0,90 & 7,5 & 5,0 & 13,7 & 27,9 & 50,2 \\
DT & 4,9 & 11,1 & 2,0 & 14,7 & 1,0 & 7,6 & 5,0 & 14,1 & 28,6 & 49,1 \\
DP & 4,9 & 12,9 & 2,1 & 15,6 & 1,0 & 9,4 & 7,0 & 17,6 & 33,2 & 51,5 \\
PD & 5,1 & 10,7 & 2,2 & 13,0 & 1,5 & 7,6 & 5,0 & 14,7 & 27,7 & 53,2 \\
E & 4,9 & 12,2 & 2,0 & 15,0 & 0,9 & 8,2 & 4,9 & 14,2 & 29,5 & 48,6 \\
G & 4,9 & 11,7 & 2,2 & 14,1 & 0,8 & 9,0 & 5,7 & 16,2 & 30,4 & 52,2 \\
A & 4,9 & 11,0 & 2,1 & 14,0 & 0,9 & 7,2 & 4,6 & 13,0 & 27,1 & 48,4 \\
\hline Sem adubo & 4,9 & 11,5 & $1,9 \mathrm{~b}$ & 14,2 & 1,0 & 7,6 & 5,2 & 14,3 & 28,7 & 49,8 \\
Com adubo & 4,9 & 11,9 & $2,4 \mathrm{a}$ & 14,4 & 1,0 & 8,6 & 5,4 & 15,3 & 28,8 & 51,2 \\
\hline CV (\%) & 3,6 & 9,3 & 32,6 & 14,5 & 13,4 & 23,4 & 33,4 & 21,9 & 11,8 & 9,1 \\
\hline
\end{tabular}

$\mathrm{CB}=$ controle Brachiaria decumbens; $\mathrm{DT}=$ dessecação total; $\mathrm{DP}=$ dessecação parcial; $\mathrm{PD}=$ Plantio direto; $\mathrm{E}=$ escarificação do solo; $\mathrm{G}=$ gradagem; $\mathrm{AG}=$ aração e gradagem; $\mathrm{M} . \mathrm{O}=$ matéria orgânica; $\mathrm{SB}=$ soma de bases; $\mathrm{CTC}=$ capacidade de troca catiônica; $\mathrm{V}(\%)=$ saturação por base; CV $(\%)=$ coeficiente de variação. Médias seguidas por letras diferentes na mesma coluna diferem entre si a $5 \%$ de probabilidade pelo teste de Tukey.

Fonte: Elaboração dos autores. 
Não foram observadas diferenças significativas entre as formas de introdução da leguminosa para os valores de $\mathrm{H}+\mathrm{Al}$, SB, CTC e V, porém foram maiores do que os encontrados por Longo, Ribeiro e Melo (2011) trabalhando com mucuna e feijão guandu consorciados com Brachiaria humídicola adubadas com (NPK). De maneira geral, a adubação pode contribuir para elevação da fertilidade do solo, o que corrobora com os resultados de Carvalho et al. (2007), testando o efeito da fertilização em Argrissolo Vermelho Amarelo com Brachiaria decumbens em monocultivo e consorciada com leguminosas. Verificaram no pasto fertilizado melhores condições químicas do solo, através de maiores teores de fósforo e CTC efetiva e menores valores de alumínio tocável em relação aos outros tratamentos. Os teores de saturação por bases do solo (V\%) variaram de 49,12 a 53,25\%, sendo maiores do que as recomendações mínimas feitas pela EMBRAPA (2000), que afirmam que o estilosantes pode crescer e produzir forragem e sementes em solos com $\mathrm{V}(\%)$ entre 30 e $35 \%$ e próximos aos recomendados por Werner et al. (1996) para valores de $50 \%$ na formação de pastos com estilosantes.

Os teores de potássio (K) não apresentaram diferenças significativas variando de 0,80 a 1,54 $\mathrm{mmol}_{\mathrm{c}} \mathrm{dm}^{-3}$. São encontradas poucas referências a respeito de potássio $(\mathrm{K})$ em capim-braquiária, mas os solos arenosos de cerrado, normalmente, são também deficientes em K. O uso é recomendado, geralmente, quando os teores estão abaixo de 1,3 mmol $_{\mathrm{c}} \mathrm{dm}^{-3}$ (VILELA et al., 2002). O potássio é bastante móvel no solo e sua absorção é altamente seletiva (CHEN; GABELMAN, 2000) e suas funções estão relacionadas com processos vitais, tais como: fotossíntese, translocação e balanço iônico (MARSCHNER, 1995).
Os macronutrientes $\mathrm{Ca}$ e $\mathrm{Mg}$, não apresentaram diferenças estatísticas entre os tratamentos (Tabela 3). O teor de $\mathrm{Ca}$ é de fundamental importância dentro da planta, pois é o elemento formador de parede celular, garantindo o desenvolvimento da parte aérea e do sistema radicular. $\mathrm{O}$ teor de $\mathrm{Mg}$ é constituinte central da molécula de clorofila, sendo que este representa $10 \%$ de todo o magnésio foliar. É considerado um ativador enzimático por excelência, e grande parte do Mg presente na planta encontra-se envolvido na regulação do $\mathrm{pH}$ celular e do balanço cátion-anion (DIAS FILHO, 2007). Os micronutrientes presentes no solo não apresentaram diferenças significativas entre os tratamentos com a presença de leguminosas e adubação fosfatada (Tabela 3). Segundo Luz, Herling e Sanchez (2011), os micronutrientes por ocorrerem no material de origem do solo de diversas formas minerais, podem ser liberados pelo intemperismo e reagem de formas variadas com as frações dos solos. Em geral, essas interações ocorrem com os óxidos de ferro e alumínio e com a matéria orgânica. A disponibilidade dos micronutrientes catiônico diminuiu com a elevação do $\mathrm{pH}$ do solo. As funções dos micronutrientes nas plantas estão ligadas com processos de ativação enzimática, etapas da fotossíntese, síntese de parede celular e estabilidade de membranas e em determinados passos do metabolismo (MARSCHNER, 1995). A intensificação da produtividade dos pastos com o emprego de adubações (principalmente nitrogenada) deve haver maior demanda de micronutrientes no sistema, principalmente de zinco (MONTEIRO; COLOZZA; WERNER, 2004). Os micronutrientes são pouco estudados, especialmente em condições de campo, sendo as leguminosas, normalmente, mais exigentes que as gramíneas (VILELA et al., 2002). 
Tabela 3. Médias dos teores de micronutrientes presentes no solo na consorciação de estilosantes Campo Grande e Brachiaria decumbens em diferentes formas de introdução da leguminosa com e sem adubação fosfatada.

\begin{tabular}{cccccc}
\hline Tratamentos & Boro & Cobre & Ferro & Manganês & Zinco \\
& $------------------------------\left(\mathrm{mg} \mathrm{dm}^{-3}\right)$ & ---------------------- \\
\hline CB & 0,17 & 0,61 & 19,62 & 17,67 & 0,59 \\
DT & 0,15 & 0,61 & 23,00 & 20,12 & 0,45 \\
DP & 0,19 & 0,61 & 27,62 & 20,74 & 1,01 \\
PD & 0,16 & 0,65 & 16,37 & 17,00 & 0,51 \\
E & 0,15 & 0,64 & 22,62 & 20,01 & 0,72 \\
G & 0,15 & 0,65 & 21,62 & 19,57 & 0,69 \\
AG & 0,15 & 0,59 & 18,37 & 19,94 & 0,49 \\
\hline Sem adubo & 0,16 & 0,62 & 20,68 & 19,50 & 0,61 \\
Com adubo & 0,16 & 0,62 & 21,96 & 19,09 & 0,66 \\
\hline CV (\%) & 14,91 & 8,84 & 24,81 & 13,27 & 28,00 \\
\hline
\end{tabular}

$\mathrm{CB}=$ controle Brachiaria decumbens; $\mathrm{DT}=$ dessecação total; $\mathrm{DP}=$ dessecação parcial; $\mathrm{PD}=$ Plantio direto; $\mathrm{E}=$ escarificação do solo; $\mathrm{G}=$ gradagem; $\mathrm{AG}=$ aração e gradagem; $\mathrm{CV}(\%)=$ coeficiente de variação. Médias seguidas por letras na mesma coluna diferem entre si a $5 \%$ de probabilidade pelo teste de Tukey.

Fonte: Elaboração dos autores.

\section{Conclusões}

A introdução do estilosantes Campo Grande em plantio direto acompanhado de técnicas como dessecação, gradagem e aração do solo contribuíram para aumentos nos teores de N-total nas raízes.

As estratégias aplicadas na recuperação de pasto degradado não apresentam diferenças entre os atributos químicos do solo para macro e micronutrientes.

A adubação fosfatada influenciou positivamente nos teores de P no solo.

\section{Referências}

ANDRADE, R. S.; STONE, L. F.; SILVEIRA, P. M. Cultura de cobertura e qualidade física de um Latossolo em plantio direto. Revista Brasileira de Engenharia Agrícola e Ambiental, Campina Grande, v. 13, n. 4, p. 411-418, 2009.

ASSOCIATION OF OFFICIAL ANALYTICAL CHEMISTS - AOAC. Official methods of analysis. 15. ed. Washington: AOAC, 1990. $1117 \mathrm{p}$.

BELONI, T.; CECATO, U.; PIOTTO, V. C.; MARI, G. C.; PINHEIRO, A. A.; STANQUEVIS, C. E. Concentração de N-total de raízes de capim-Mombaça adubado e irrigado, sob pastejo. In: REUNIÃO ANUAL
DA SOCIEDADE BRASILEIRA DE ZOOTECNIA, 49., 2012, Brasília. Anais... Brasília: SBZ, 2012. p. 1-3.

CARVALHO, F. G.; BURITY, H. A.; SILVA, L. E. S. F.; SILVA, V. N.; SILVA, A. J. N. Efeito sazonal e de sistemas de manejo com pastagens de Brachiaria decumbens Stapf sobre as características químicas num Argissolo Vermelho Amarelo. Acta Scientiriarum Agronomy, Maringá, v. 29, n. 1, p. 1-7, 2007.

CECATO, U.; JOBIM, C. C.; REGO, F. C. A.; LENZI, A. Sistema radicular - componente esquecido das pastagens. In: SIMPÓSIO SOBRE O MANEJO ESTRATÉGICO DA PASTAGEM, 2004, Viçosa. Anais... Viçosa: UFMG, 2004. p. 159-207.

CHEN, J.; GABELMAN, W. H. Morphological and physiological characteristics of tomato roots associated with potassium acquisition efficiency. Scientia Horticulture, Madison, v. 83, n. 13, p. 213-225, 2000.

CENTRO INTEGRADO DE INFORMAÇÕES AGROMETEROLÓGICAS - CIIAGRO. Mapas da resenha agrometerológica. Andradina: São Paulo, 2012. Disponível em: <http://www.ciiagro.sp.gov.br/resenha/ index.asp>. Acesso em: 28 jul. 2012.

CORDEIRO, F. C. Atributos edáficos em área de pastagem plantada em relevo movimentado no noroeste do Estado do Rio de Janeiro. 2006. Tese (Mestrado em Agronomia) - Universidade Federal Rural do Rio de Janeiro, Rio de Janeiro. 
CORSI, M.; MARTHA, J. R.; PAGOTTO, D. S. Sistema radicular: dinâmica e resposta a regimes de desfolha. In: MATTOS, W. R. S. (Ed.). A produção animal na visão dos brasileiros. Piracicaba: FEALQ, 2001. p. 838-852.

CUNHA, F. F.; RAMOS, M. M.; ALENCAR, C. A. B.; MARTINS, C. E.; CÓSER, A. C.; OLIVEIRA, R. A. Sistema radicular de seis gramíneas irrigadas em diferentes adubações nitrogenadas e manejos. Acta Scientiriarum Agronomy, Maringá, v. 32, n. 2, p. 351357, 2010.

CUNHA, R.; SILVEIRA, P. M.; STONE, P. C.; SANTOS, G. G. Atributos químicos de solo cultivado com diferentes culturas de cobertura. Pesquisa Agropecuária Tropical, Goiás, v. 40, n. 3, p. 283-290, 2010.

DIAS FILHO, M. B. Degradação de pastagens: processos, causas e estratégias de recuperação. 3. ed. Belém: Embrapa Amazônia Oriental, 2007. 33 p.

EMPRESA BRASILEIRA DE PESQUISA AGROPECUÁRIA - EMBRAPA. Estilosantes Campo Grande: estabelecimento, manejo e produção animal. Campo Grande: Embrapa, 2000. 8 p. (Embrapa Gado de Corte. Comunicado técnico, 61).

FOLLETT, R. H.; FOLLETT, R. F.; HALVORSON, A. D. Use of a chlorophyll meter to evaluate the nitrogen status of dryland winter wheat. Communications in Soil Science and Plant Analysis, New York, v. 23, n. 12, p. 687-689, 1992.

GUGGENBERGER, G.; HAUMEIER, L; THOMAS, R. J.; ZECH, W. Assessing the organic phosphorus status of an Oxisol under tropical pastures following native savanna using 31P NMR spectroscopy. Biology and Fertility os Soils, Bayreuth, v. 23, n. 3, p. 332-339, 1996.

LEMAIRE, E.; CHAPMAN, D. Tissue flows in grazed plant comunities. In: HODGSON, I.; ILLIUS, A. W. (Ed.). The ecology and management of grazing systems. [S.1.: s.n], 1996. p. 3-36.

LONGO, R. M.; RIBEIRO, A. I.; MELO, W. J. Uso da adubação verde na recuperação de solos degradados por mineração na floresta amazônica. Solos e Nutrição de Plantas, Campinas, v. 70, n. 1, p. 139-146, 2011.

LOPES, J.; EVANGELISTA, A. R.; FORTES, C. A.; PINTO, J. C.; FURTINI NETO, A. E.; SOUZA, R. M. Nodulação e produção de raízes do Estilosantes Mineirão sob efeito de calagem, silicatagem e doses de fósforo. Ciência Agrotécnica, Lavras, v. 35, n. 1, p. 99-107, 2011.

LUZ, P. H. C.; HERLING, V. R.; SANCHEZ, J. M. D. Calagem e adubação: Estabelecimento, manutenção e produtividade dos pastos. In: SIMPOSIO DE PRODUÇÃO ANIMAL A PASTO, 2011, Maringá.
Anais... Maringá: UEM, 2011.p. 105-106.

MARSCHNER, H. Mineral nutrition of higher plants. 2. ed. Londres: Academic Press, 1995. p. 347-364.

MONTEIRO, F. A.; COLOZZA, M. T.; WERNER, J. C. Enxofre e micronutrientes em pastagens. In: SIMPÓSIO SOBRE MANEJO DE PASTAGENS, 21., Piracicaba, 2004. Anais... Piracicaba: Fealq, 2004. p. 279-302.

MULLER, M. M. L.; GUIMARÃES, M. F.; DESJARDINS, T.; MARTINS, P. F. S. Degradação de pastagens na Região Amazônica: propriedades físicas do solo e crescimento de raízes. Pesquisa Agropecuária Brasileira, Brasília, v. 36, n. 11, p. 1409-1418, 2001.

OBERSON, A.; FRIESEN, D. K.; RAO, I. M.; BÜHLER, S.; FROSSARD, E. Phosphorus transformations in an Oxisol under contrasting land-use systems: the role of the soil microbial biomass. Plant and Soil, Netherlands, v. 237, n. 34, p. 197-210, 2001.

PAGOTTO, D. S. Comportamento do sistema radicular, reservar orgânicas e mineralização líquida do nitrogênio do solo em pastagem irrigada de capim-Tanzânia submetida a diferentes intensidades de pastejo. 2001. Dissertação (Mestrado em Agronomia) - Escola Superior de Agricultura Luiz de Queiroz. Universidade de São Paulo, São Paulo.

PAULINO, M. F.; DETMANN, E.; VALADARES FILHO, S. C. Suplementação animal em pasto: energética ou protéica? In: SIMPÓSIO SOBRE MANEJO ESTRATÉGICO DA PASTAGEM, 3., 2006, Viçosa. Anais... Viçosa: SIMFOR, 2006. p. 359-392.

QUADROS, D. G.; RODRIGUES, L. R. A.; RODRIGUES, T. J. D.; RAMOS, A. K. B.; PAROLIN, F. J. T. Acúmulo de massa seca e dinâmica do sistema radicular do Estilosantes Mineirão submetido a duas intensidades de desfolhação. Ciência Animal Brasileira, Goiás, v. 5, n. 4, p. 113-122, 2004.

RODRIGUES, R. C.; MOURÃO, G. B.; VALINOTE, A. C.; HERLING, V. R. Reservas orgânicas, relação parte aerea-raiz e C-N e eliminação do meristema apical no capim-Xaraés sob doses de nitrogênio e potássio. Ciência Animal Brasileira, Goiás, v. 8, n. 3, p. 505-514, 2007.

SANTOS, H. G.; JACOMINE, P. K. T.; ANJOS, L. H. C. (Ed.). Sistema brasileiro de classificação de solos. Rio de Janeiro: Embrapa Solos, 2006. 306 p.

STATISTICAL ANALYSIS SYSTEM INSTITUTE SAS. SAS/STAT Procedure guide personal computers. 9. ed. Cary: NC. Inst, 1999. 334 p. 
SOARES FILHO, C. V. Características morfogênicas, perdas de nitrogênio por volatização, reservas orgânicas e sistema radicular do capim-Tanzânia fertilizado com doses de nitrogênio. 2009. Tese (Livre-Docência em Medicina Veterinária) - Universidade Estadual Paulista. Faculdade de Medicina Veterinária, Araçatuba.

VILELA, L.; SOARES, W. V.; SOUSA, D. M. G.; MACEDO, M. C. M. Calagem e adubação para pastagens. In: SOUZA, D. M. G.; LOBATO, E. (Ed.). Cerrado: correção do solo e adubação. Planaltina: Embrapa-CPAC, 2002. cap. 14, p. 367-382.
VOLPE, E.; MARCHETTI, M. E.; MACEDO, M. C. M.; EDGARD JUNIOR, J. R. Renovação de pastagem degradada com calagem, adubação e leguminosa consorciada em Neossolo Quartzarênico. Acta Scientiarum, Maringá, v. 30, n. 1, p. 131-138, 2008.

WERNER, J. C.; PAULINO, V. T.; CANTARELlA, H.; RAIJ, B.; CANTARELLA, H.; Forrageiras. In: QUAGGIO, J. A.; FURLANI, A. M. C. Recomendações de adubação e calagem para o estado de São Paulo. 2. ed. Campinas: Instituto Agronômico e Fundação IAC, 1996. p. 263-273. (Boletim técnico, 100). 